\title{
KOMPOSIT FIBER REINFORCED PLASTIC SEBAGAI MATERIAL BODI KAPAL BERBASIS FIBERGLASS TAHAN API
}

\author{
Adella Hotnyda Siregar ${ }^{1}$, Budiman Adi Setyawan ${ }^{2}$, Amir Marasabessy ${ }^{3}$ \\ Fakultas Teknik UPN ”Veteran "Jakarta \\ Email: hs.adella@yahoo.com
}

\begin{abstract}
The aim of the research is to analyze resin in boat body base on composite fiber reinforced plastic with fire resistant/flame retardant. The resin used polyester resin Yucalac 157 BQTN-EX and Yucalac BQTN-FR. Experimental method is used in this research and speciment composite made with hand lay up method and then observed with flammability test UL 94 standard. The result show that composite with Yucalac 157 BQTN- FR resin higher flammability and linier burning rate less than Yucalac 157 BQTN-EX resin.
\end{abstract}

Kata Kunci: Flammability , linier burning rate, resin polyester

\section{PENDAHULUAN}

Kapal ikan kapasitas 30 GT Type Purse Seine berbahan komposit sering digunakan nelayan untuk menangkap ikan. Bahan yang digunakan adalah komposit-fiberglass. Dalam operasional kapal bahan komposit-fiberglass ini rawan terjadi kebakaran. Namun bahan fibers glass kurang tahan terhadap panas yang tinggi sehingga diperlukan penyempurnaan tahan api pada lapisan terluarnya Sehingga perlu diberikan penyempurnaan tahan api agar keselamatan kapal ikan terjamin dengan baik

Komposit didefinisikan sebagai kombinasi antara dua material atau lebih yang berbeda bentuknya, komposisi kimianya, dan tidak saling melarutkan antara materialnya dimana material yang satu berfungsi sebagai penguat dan material yang lainnya berfungsi sebagai pengikat untuk menjaga kesatuan unsur-unsurnya. Secara umum terdapat dua kategori material penyusun komposit yaitu matrik dan reinforcement Dalam penelitian ini sebagai matriks digunakan resin polyester Yukalac 157 BQIN-EX dan sebagai reinforced digunakan serat glass E jenis Woven roving 800 dan Chopped Strand Mat CSM glass 300,450. Pengujian yang dilakukan pada penelitian ini adalah pengujian tahan api dengan mengacu pada standart pengujian UL 94. Sedangkan penelitian ini menganalisis pengaruh penggunaan resin Yucalac BQTN-EX dan Yucalac BQTN-FR terhadap ketahanan api komposit. Susunan laminasi yang digunakan adalah susunan yang banyak dipakai dalam material produk komersil yaitu kombinasi serat acak dan serat anyaman yang disusun seeara bergantian. Susunan laminasi sambungan sarna dengan susunan laminasi komposit induk. Metode yang digunakan dalam penelitian ini adalah metode eksperimen dengan menggunakan 2 jenis resin Hasil penelitian berupa produk komposit-fiberglass tahan api akan dimuat pada jurnal nasional terakreditasi.

\section{Bahan Komposit (Fiber Reinforced Plastic)}

Material komposit didefinisikan sebagai kombinasi antara dua material atau lebih yang berbeda bentuknya, komposisi kimianya, dan tidak saling melarutkan antara materialnya (Smith,1993). Terdiri dari dua atau lebuh bahan yang berbeda yang membentuk suatu kesatuan (Van Vlack, 1991). Merupakan satu kesatuan dimana material yang satu berfungsi sebagai penguat dan material yang lainnya berfungsi sebagai pengikat untuk menjaga kesatuan unsur-unsurnya.

Komposit adalah bahan hibrida yang terbuat dari resin polimer diperkuat dengan serat, menggabungkan sifat-sifat mekanik dan fisik. Bahan komposit pada umumnya terdiri dari dua unsur, yaitu serat (fiber) sebagai bahan pengisi dan bahan pengikat serat-serat tersebut yang dikenal dengan matriks. Bahan serat digunakan bahanbahan yang kuat, kaku, dan getas, sedangkan bahan matriksnya dipilih bahan-bahan yang liat, lunak dan tahan terhadap perlakuan kimia.Komposit pada umumnya terdiri dari dua fasa yaitu : Matriks /penguat pada pembuatan komposit, dan Reinforcement atau filler / Fiber

Salah satu bagian utama dari komposit adalah reinforcement (penguat) yang berfungsi sebagai penanggung beban utama pada komposit. Adanya dua penyusun komposit atau lebih menimbulkan beberapa daerah dan istilah penyebutannya. Matriks (penyusun dengan fraksi volume terbesar), penguat (penahan beban utama), Interphase adalah pelekat antar dua penyusun, 
interface adalah permukaan fasa yang berbatasan dengan fasa lain. (Surdia, 2005) .

Bahan utama fiberglass yang digunakan untuk bodi kapal sebagai berikut: dimana jumlah kebutuhan untuk produksi ditentukan dengan menggunakan maxsurfprograme.

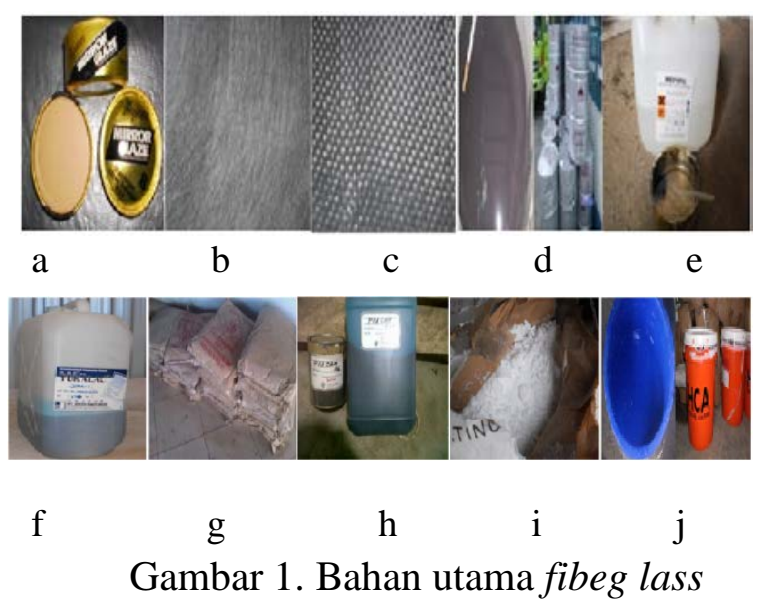

\section{Keterangan :}

(a) mirror glass,(b) Choped Srand mat, (c) Woven Roving, (d) Resin Yukalac 157, (e) Katalis Pholivinyl Alcohol,(f) Talk, (g) Cobalt Herocyl, (h) Gelcoat-pegment, Aceton

Choped strand mat (CSM) adalah sebutan untuk serat (fiber) yang berwarna putih dengan susunan tidak beraturan. Fungsinya sebagai penguat resin terutama pada pembuatan lembaran agar tidak mudah retak/pecah. Serat fiberglass woven roving (WR 800 ) adalah istilah ropping digunakan untuk serat halus berwarna putih yang susunannya beraturan seperti serat pada karung, Katalis yang digunakan dalam penelitian ini adalah metil etil keton peroksida (mekpo) dengan bentuk cair, berwarna bening. Fungsi dari katalis ini adalah mempercepat terjadinya proses pengeringan pada bahan matrik suatu komposit. Resin poliester Yukalac 157 BTQN-EX dan resin poliester Yukalac 157 BTQN-FR Resin merupakan resin tidak jenuh. Merupakan polimer zat organik yang terdiri dari unsur-unsur karbon, hidrogen dan oksigen yang berbentuk padat atau cair. Ditinjau dari sifatnya resin berfungsi sebagai bahan pengikat/lem.(Justus Kimia). PVA adalah bahan ini berupa cairan kimia berwarna biru menyerupai spiritus. Berfungsi untuk melapis antara master mal/cetakan dengan bahan fibreglass. Tujuannya adalah agar kedua bahan tersebut tidak saling menempel, sehingga fiberglass hasil cetakan dapat dilepas dengan mudah dari master mal atau cetakannya. Talk sebagai filler material/pengental/pemadat material, berfungsi sebagai campuran adonan fiberglass agar keras dan agak lentur. Cobalt-herosil adalah Cairan kimia ini berwarna kebiru-biruan berfungsi sebagai bahan aktif pencampur katalis agar cepat kering, terutama apabila kualitas katalisnya kurang baik dan terlalu encer. Pigmen adalah pewarna resin berupa pasta. Penggunaannya harus dicampur dengan resin terlebih dahulu. Aseton sebagai pelarut gelcoat.

Resin poliester tidak jenuh terdiri dari : a) resin poliester. Resin ini telah dipakai secara meluas dan mudah diperoleh di pasaran secara umum. Sifat- sifat resin ini adalah sebagai berikut: isolator listrik, kekuatan tinggi, flexible, daya adhesive baik, dan harga relatif murah. b) Resin Epoxy. Resin Epoxy memiliki karakteristik yang langsung ditunjukan dalam hubungan antara ciri struktur dengan sifat tahan terhadap panas, daya adhesive baik,t ahan korosi, harga relatife lebih tinggi dari resin Poliester, dam c) Resin phenolic Sifat mekanik dari resin phenolic lebih rendah dari resin epoxy dan poliester, tetapi resin ini tahan benturan dan panas. Dari jenis-jenis resin tersebut di atas masih banyak lagi jenis resin lain, biasanya sudah diproduksi langsung bersatu dengan material fiber glass yang disebut Prepreg.

Resin poliester tak jenuh (UPR) merupakan jenis resin termoset atau lebih populernya sering disebut poliester saja. UPR berupa resin cair dengan viskositas yang cukup rendah, mengeras pada suhu kamar dengan penggunaan katalis tanpa menghasilkan gas sewaktu pengesetan seperti banyak resin termoset lainnya..Sifat-sifat poliester dapat dilihat sebagai berikut : kuat tarik $40 \mathrm{Mpa}$, elongasi 1,8 \%, kuat tekan 5,5 Mpa, modulus elastisitas $300 \mathrm{Gpa}$, kuat Impak 0,4 J/m, densitas (kerapatan) 1,1 kg/m, rasio Poison 0.33 (Surdia, 2005) . Karena sifat-sifat ini, poliester sering digunakan secara luas sebagai plastik penguat serat (fiber plastic reinforcement $=\mathrm{FPR}$ ) dengan menggunakan serat gelas. Terdapat pengaruh penambahan serat pada jenis resin yang berbeda pada kekuatan impak komposit dari poliester.

Resin Poliester) (UPR) yang digunakan dalam penelitian ini diperoleh dari toko bahan kimia Justus Sakti, Jl Danau Sunter Jakarta, dengan kode produk Yukalac 157 BQTN. -EX. Unsaturated Polyester Resin (UPR) merupakan jenis resin termoset atau polyester. Unsaturated Polyester Resin (UPR) Yukalac 157 BQTN-EX adalah jenis resin orthophtalic dengan waktu curing cepat, thixotropic, dan tanpa lilin, cocok pembuatan komposit FRP dengan metode hand lay up dan spray up molding. Yukalac Yukalac 157 BQTN-EX Series telah tersertifikasi BKI. (Justus Kimia Raya, 2013). Tipe resin ini tahan terhadap air (suhu normal) dan asam lemah. Komposisi adalah kondensasi produk dari asam dibasic acids dan dihydric alcohols, dilarutkan dalam monomer stiren. Sifat fisik sebagai berikut :dengan berat jenis pada 
temperatur $25 \hat{\mathrm{A}}{ }^{\circ} \mathrm{C}$ sebesar $1.12 \mathrm{~g} / \mathrm{cm} 3$, tidak larut dalam air berbau seperti stiren berat jenis (udara $=1$ ) : $3.6 \mathrm{~m}$, titik nyala/Flash point terbuka sebesar : $34 \hat{A}^{\circ} \mathrm{C}$ (ASTM D 1310/67) - Flash point tertutup : $31 \hat{A}^{\circ} \mathrm{C}$ (ASTM D 93/66), batas eksplosif di udara : dibawah : $1.1 \%$ volume, diatas : $6.1 \%$ volume, Temperatur nyala sebesar $490 \hat{A}^{\circ} \mathrm{C}$

Resin YUKALAC 157 BQTN-FR, adalah jenis resin orthophtalic dengan waktu curing cepat, thixotropic, dan tanpa lilin, cocok pembuatan komposit FRP dengan metode hand lay up dan spray up molding. Yukalac Yukalac 157 BQTN-EX Series telah tersertifikasi BKI Certified. (Justus Kimia Raya, 2013). Tipe resin ini tahan terhadap air (suhu normal) dan asam lemah. Komposisi adalah kondensasi produk dari asam dibasic acids dan dihydric alcohols, dilarutkan dalam monomer stiren. Sifat fisik gengan berat jenis pada temperature 25Â ${ }^{\circ} \mathrm{C}: 1.12 \mathrm{~g} / \mathrm{cm}^{3}$, tidak larut dalam air berbau seperti stiren berat jenis (udara=1) : $3.6 \mathrm{~m}$ Titik nyala/Flash point terbuka sebesar : $34 \hat{A}^{\circ} \mathrm{C}$ (ASTM D 1310/67) - Flash point closed cup : $31 \hat{\mathrm{A}}^{\circ} \mathrm{C}$ (ASTM D 93/66) - Batas eksplosif di udara air : dibawah : $1.1 \%$ volume - diatas : $6.1 \%$ volume, Temperatur nyala sebesar $490 \hat{\mathrm{A}}^{\circ} \mathrm{C}$.

\section{Komposit Tahan Api}

Bahan mudah terbakar (flammable) adalah bahan yang akan terus terbakar meskipun tanpa dibantu bila terkena api. Sedangkan bahan tahan api atau non flammable (flame proof fire resistant) merupakan bahan yang tidak terbakar bila dikenai api.

Flame retardant adalah istilah yang dipakai untuk menerangkan sifat tidak mudah terbakar pada komposit, dimana pembakaran berlangsung lambat dan api akan mati dengan sendirinya bila sumber nyala api ditiadakan. Pada peristiwa pembakaran bahan terjadi dekomposisi kimia bahan dan menghasilkan suatu bahan tertentu yang mudah menguap dan dapat terbakar. Bila nyala api dipadamkan maka akan meninggalkan residu seperti karbon. Sifat kain pada pembakaran ditentukan oleh jumlah bahan yang menguap dan perlu diketahui bahwa sisa pembakaran (arang) juga dapat membara dan meneruskan pembakaran. Pembakaran akan berlangsung cepat jika struktur bahan mendukung penyimpanan udara atau oksigen sehingga meneruskan pembakaran setelah terjadi proses penyalaan pada bahan.

\section{Proses Terbakarnya Bahan .Komposit}

Proses pembakaran pada dasarnya terdiri dari proses pemanasan, dekomposisi, penyalaan, dan perambatan. Panas yang timbul akibat adanya sumber dari luar akan menyebabkan proses pembakaran. Panas akan menaikkan suhu bahan sampai degradasi dan dekomposisi pada struktur polimer, dimana dari polimer biasanya akan terbentuk sisa karbon. Selanjutnya padatan akan terurai menghasilkan gas, baik gas yang mudah terbakar maupun tidak. Jumlah relatif dari gas yang mudah terbakar maupun tidak mudah terbakar yang dihasilkan tergantung pada sifat bahan, kondisi lingkungan, dan zat kimia yang digunakan.

Proses pembakaran biasanya dibagi menjadi proses menyala (flaming), membara (glowing) dan memijar (smoldering) sebagai berikut:

a) Nyala (flame)adalah proses pembakaran yang digambarkan sebagai suatu proses terbakarnya gas yang terurai dipermukaan. Proses dekomposisi thermal yang terjadi pada komposit selalu didahului oleh proses nyala. Proses nyala ini menghasilkan gas, cairan, arang dan padatan. Penyalaan merupakan proses pembakaran yang terjadi secara eksotermis yang terdiri dari uap yang mudah terbakar dan terurai dipermukaan bahan.

b) Bara (glow)merupakan proses eksotermis yang terjadi dipermukaan dan berada pada fase gas yang hanya berada diatas permukaan. Keadaan ini berlangsung dalam kondisi jumlah oksigen yang melimpah. Bahan dengan penyempurnaan tahan bara sering diperoleh bersama-sama dengan sifat tahan nyala api. Zat penghambat nyala yang berfungsi sebagai penghambat bara misalnya fosfat, tetapi beberapa dari jenis lainnya seperti sufamat, mempunyai daya penahan bara yang kecil. Panas pembakaran pada poliester sekitar $400-500{ }^{\circ} \mathrm{C}$, sedangkan suhu nyala bara api sekitar $600{ }^{\circ} \mathrm{C}$.

c) Pijar (smolder) secara umum terjadi dibawah permukaan dan biasanya dalam kondisi persediaan oksigen yang sangat sedikit. Proses pemijaran ini terjadi secara lambat, dan biasanya disertai dengan keluarnya asap, tetapi tanpa disertai adanya nyala atau bara kemampuan meneruskan pemijaran sangat dipengaruhi oleh adanya panas dari reaksi eksotermis yang ditahan didekat area yang sdang berpijar. Suhu minimum yang dibutuhkan untuk mempertahankan pemijaran dipengaruhi oleh karakteristik bahan ketika mengalami prosesoksidasi dan jumlah oksigen yang ada. Pada kondisi kandungan okasigen yang lebih besar, dengan suhu yang lebih rendah proses pembaraan dapat bertahan lebih lama. Metoda yang baik yang dapat digunakan untuk mencegah proses pemijaran adalah dengan menghilangkan panas dengan segera dari daerah yang mengalami proses oksidasi.

Tujuan Penelitian adalah membandingkan hasil laminasi resin Yucalac BQTN EX dan resin Yucalac BQTN FR yang digunakan untuk pembuatan bodi kapal dan ketahanan api untuk bodi kapal, sedangkan manfaat penelitian adalah membuat bodi kapal yang tahan api. 


\section{METODE PENELITIAN}

Penelitian dilakukan di galangan kapal fiberglass CV.Cisanggarung Putra Mandiri Marunda. Jakarta Utara sesuai gambar 1. dengan kegiatan usaha pelayanan jasa produksi bangunan baru dan reparasi kapal berbahan fiber glass.

Bahan yang digunakan sebagai berikut: Bahan adalah resin Resin Yukalac 157 BQTN-EX dan resin Resin Yukalac 157 BOQTN-FR yang berfungsi sebagai matrik dan CS Matt 300,CS Mat 450 dan woven roving 800 dan Gelcoat yang terdiri dari pigmen, herosil,aceton dan cobalt dengan resep

Tabel 1. Resep Pembuatan Bodi kapal $\quad$ (FRP)

\begin{tabular}{|c|c|c|c|}
\hline \multicolumn{2}{|l|}{ Jenis Resin } & $\begin{array}{l}\text { Resin } \\
\text { Yukalac } \\
157 \\
\text { BQTN- } \\
\text { EX } \\
\end{array}$ & $\begin{array}{l}\text { Resin } \\
\text { Yukalac } \\
157 \\
\text { BOQTN- } \\
\text { FR } \\
\end{array}$ \\
\hline \multirow[t]{4}{*}{$\begin{array}{ll}\text { Laminasi } & \text { serat } \\
\text { fiberglass } & \end{array}$} & -Katalis & $\begin{array}{l}(1 \mathrm{~s} / \mathrm{d} 1,5) \\
\%, \\
\text { kondisi } \\
\text { tertentu } \\
2 \%\end{array}$ & $\begin{array}{l}(1 \mathrm{~s} / \mathrm{d} 1,5) \\
\%, \\
\text { kondisi } \\
\text { tertentu } \\
2 \%\end{array}$ \\
\hline & $\begin{array}{l}\text { CS } \\
\text { Mat300 }\end{array}$ & $\begin{array}{l}(0.9-1,0) \\
\mathrm{kg} / \mathrm{m} 2\end{array}$ & $\begin{array}{l}(0.9-1,0) \\
\mathrm{kg} / \mathrm{m} 2\end{array}$ \\
\hline & $\begin{array}{l}\text { CSMat } \\
450\end{array}$ & $\begin{array}{l}(1,1-1,2) \\
\mathrm{kg} / \mathrm{m} 2\end{array}$ & $\begin{array}{l}(1,1-1,2) \\
\mathrm{kg} / \mathrm{m} 2\end{array}$ \\
\hline & $\begin{array}{l}\text { WR } \\
800\end{array}$ & $\begin{array}{l}(1,5-1,6) \\
\mathrm{kg} / \mathrm{m} 2\end{array}$ & $\begin{array}{l}(1,5-1,6) \\
\mathrm{kg} / \mathrm{m} 2\end{array}$ \\
\hline \multirow[t]{3}{*}{ Pembuatan gelcoat } & Pigmen & $(8-10) \%$ & $(8-10) \%$ \\
\hline & Herosil; & $(0,6-1) \%$ & $(0,6-1) \%$ \\
\hline & Cobalt & $\begin{array}{l}(1,0-1,5 \\
\%)\end{array}$ & $\begin{array}{l}(1,0-1,5 \\
\%)\end{array}$ \\
\hline
\end{tabular}

Tahapan penelitian sebagai berikut:a) Survei dan Pengumpulan dan identifikasi data bodi kapal berbahan fiberglass, b)Percobaan menggunakan resin Yucalac 157 BOQTN_EX dan resin Yucalac 157 BQTN- FR, c) Pengujian uji bakar komposit dengan metode UL 94 dan analisis komposit tahan api, d) Menyusun laporan, dan seminar dan e). Draft publikasi hasil penelitian untuk jurnal nasional terakreditasi dan bahan ajar.

\section{Pembuatan Spesimen}

Spesimen komposit dibuat dengan metode hand lay up. Dimana dibuat 6 lapis Dengan perbandingan volume fraksi antara matriks dengan serat dibuat konstan. Pembuatan spesimen dimulai dengan penimbangan massa resin dan partikel dengan menggunakan timbangan digital. Campuran tersebut ditambah hardener MEKPO dan diaduk kembali seperti di atas. Komposisi perbandingan volume antara resin phenolic : promoter P-EX : hardener $\mathrm{MEKPO}=100: 0,5: 2$. Selanjutnya, campuran resin phenolic tersebut diberi gelcoat dan diaduk kembali hingga campuran merata. Lembaran spesimen komposit tersebut dibersihkan dan difinishing dengan menggunakan menggunakan gelcoat Campuran tersebut dituangkan di dalam cetakan spesimen dilakukan penekanan secara manual. Spesimen dapat diambil dari cetakan setelah mengeras selama sekitar 1-2 jam.

Pengujian Bakar.

Pengujian bakar dilakukan dengan menggunakan test UL 94. Pengujian dilakukan dengan metode uji rate of burning dan time of burning pada posisi sampel horisontal. Posisi tabung pembakaran horisontal mengarah pada ujung spesimen uji. Bahan bakar yang digunakan adalah gas metana dan tinggi api yang disyaratkan $20 \mathrm{~mm}$ dan jarak terdekat ujung burner dengan spesimen adalah $2 \mathrm{~mm}$. Pengamatan yang dilakukan meliputi pengamatan waktu penyalaan (time of burning) dan laju pembakaran (rate of burning) sepanjang $75 \mathrm{~mm}$

Spesimen uji adalah komposit dengan ukuran panjang sebesar $125 \pm 5 \mathrm{~mm}$ dan lebar sebesar $13.0 \pm 0.5 \mathrm{~mm}$. Minimum ketebalan 3.0 ($0.0+0.2)$ mm sebagai berikut :.

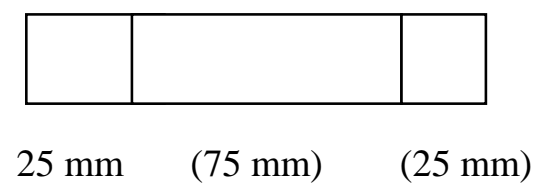

Kemudian dilihat setelah dibakar yaitu specimen terbakar setelah sumber api dihilangkan, Waktu bakar yaitu panjang bahan terbakar dibawah kondiss khusus setelah sumber api dijauhkan. Setelah bara yaitu saat bahan membara, setelah bara atau jika tidak ada bara setelah sumber api dihilangkan.

\section{Prosedur pengujian}

1) Sampel yang sudah dipreparasi sesuai ukuran dan dikondisikan pada temperature $23{ }^{\circ} \mathrm{C}$ dan RH $50 \%$ selama 48 jam , diberi tanda dengan jarak $25 \pm 1 \mathrm{~mm}$ dan $100 \pm$ $1 \mathrm{~mm}$ dari ujung sampel.

2) Ujung sampel yang dekat dengan tanda 25 mm di- clamp secara horisontal dan dan membentuk sudut $45 \pm 2$ derajat terhadap sumbu horizontal sampel.

3) Letakkan pembakar jauh dan sampel . Nyalakan pembakar, atur suplai gas dan udara yang masuk ke pembakar sehingga menghasilkan nyala api biru setinggi $20 \pm$ $1 \mathrm{~mm}$ tanpa ujung berwarna kuning

4) Letakkan pembakar pada ujung sampel yang bebas dengan kedalaman $1 \mathrm{~mm}$ dan membentuk

5) Jika nyala api sudah mencapai tanda $25 \mathrm{~mm}$ penghitungan waktu untuk menghitung laju bakar dimulai 
6) Rekam waktu yang dibutuhkan untuk membakar sampel dan tanda $25 \mathrm{~mm}$ hingga $100 \mathrm{~mm}$. Jika nyala api padam sebelum mencapai tanda $100 \mathrm{~mm}$ catat waktu ketika api padam dan jarak sampel yang terbakar.

7) Lakukan uji minimal sebanyak tiga kali.

Posisi tabung pembakaran horizontal mengarah pada ujung spesimen uji. Bahan bakar yang digunakan adalah gas metana dan tinggi api yang disyaratkan $20 \mathrm{~mm}$ dan jarak terdekat ujung burner dengan spesimen adalah $2 \mathrm{~mm}$. Pengamatan yang dilakukan meliputi pengamatan waktu penyalaan (time of burning) dan laju pembakaran (rate of burning) sepanjang $75 \mathrm{~mm}$. Pengujian tahan api sesuai dengan UL 94, Kondisi Uji Flammability Horizontal Sampel Flat Fiber Laminasi Resin sebagai berikut : prakkondisi pada $23^{\circ} \mathrm{C}$; $50 \%$; 48 Jam,metode uji UL-94 - 2013 (horizontal - HB) dan dimensi sampel (p*l) $127 \mathrm{~mm}$ x $13 \mathrm{~mm}$ dan panjang bakar $75 \mathrm{~mm}$,

Skema posisi stainless steel pada spesimen uji uji tahan api

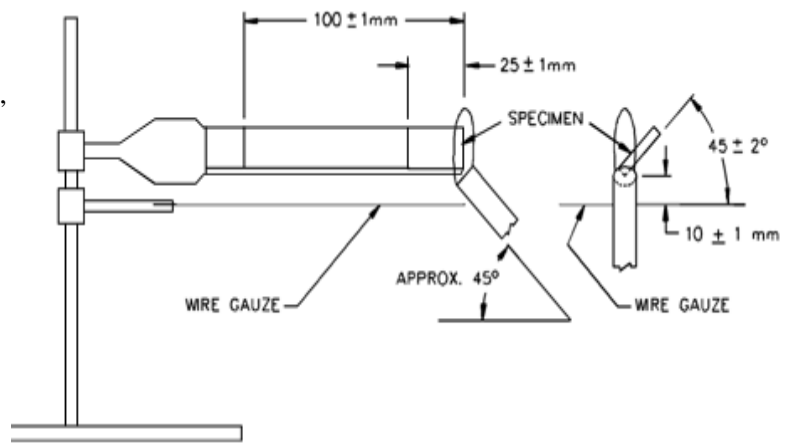

Gambar 2. Alat Horizontal Burning

Test untuk Klasifikasi HB

\section{PEMBAHASAN}

Hasil pengujian bakar dengan resin Yucalac 157 BQTN -EX dan Yucalac 157 BQTN -FR ditunjukkan pada tabel dibawah ini.

Tabel 3. Hasil Flammability Horizontal Sampel Flat Fiber Laminasi Resin

\begin{tabular}{|r|l|c|l|}
\hline $\begin{array}{c}\text { N } \\
\text { o }\end{array}$ & Nama Sampel & $\begin{array}{c}\text { Laju Bakar } \\
(\mathrm{mm} / \mathrm{min})\end{array}$ & $\begin{array}{c}\text { Kelas } \\
\text { HB* }\end{array}$ \\
\hline 1 & $\begin{array}{l}\text { Flat Fiber Laminasi } \\
\text { Resin FR }\end{array}$ & $16.2 \pm 0.5$ & Ya \\
\hline 2 & $\begin{array}{l}\text { Flat Fiber Laminasi } \\
\text { Resin } 157\end{array}$ & $22.8 \pm 0.3$ & Ya \\
\hline \multicolumn{3}{|c|}{$\begin{array}{l}\text { *Terklasifikasi HB jika: } \\
\text { atau } 3 \mathrm{~mm} \leq \text { ketebalan } \leq 13 \mathrm{~mm}, \text { laju bakar }<40 \mathrm{~mm} / \mathrm{min}, \\
\text { 2. Ketebalan }<3 \mathrm{~mm} \text {, laju bakar }<75 \mathrm{~mm} / \mathrm{min}\end{array}$}
\end{tabular}

Laju bakar Flat Fiber Laminasi Resin Yucalac 157 BQTN FR lebih kecil dari pada sampel Flat Fiber Laminasi Resin 157 BQTN EX yakni berturut-turut sebesar $16.2 \pm 0.5 \mathrm{~mm} / \mathrm{min}$ dan $22.8 \pm 0.3 \mathrm{~mm} / \mathrm{min}$, sehingga dapat disimpulkan bahwa sampel Flat Fiber Laminasi Resin 157 BQTN FR terbakar lebih lama dibandingkan dengan sampel Flat Fiber Laminasi Resin Laminasi Resin 157 BQTN EX. Hal ini disebabkan Resin Yucalac 157 BQTN FR mempunyai sifat flame retardant dan bersifat resin thermosetting sehingga pada saat dibakar, resin akan menghambat nyala api.

Pengamatan dari data-data hasil pengujian ternyata menunjukan hasil yang bervariasi. Bagus atau tidaknya ketahanan terhadap api pada komposit sendiri diindikasikan dengan lamanya laju bakar. Semakin kecil laju bakar maka semakin bagus ketahanan komposit terhadap api. Sehingga yang seharusnya komposit itu bersifat cepat terbakar akibat dari adanya senyawa karbon ( C ) dan oksigen ( $\mathrm{O}$ ) membentuk $\mathrm{CO}$ dan $\mathrm{CO} 2$ diredam oleh resin.Sampel Flat Fiber Laminasi Resin Yucalac 157 BQTN FR terbakar sampai dengan 40 mm (tanda $25 \mathrm{~mm}+15 \mathrm{~mm}$ ) dari titik awal bakar (Gambar 3), sedangkan sampel Flat Fiber laminasi Resin Yucalac 157 BQTN-EX terbakar habis hingga tanda $100 \mathrm{~mm}$ artinya seluruh panjang bakar terbakar (gambar 4).
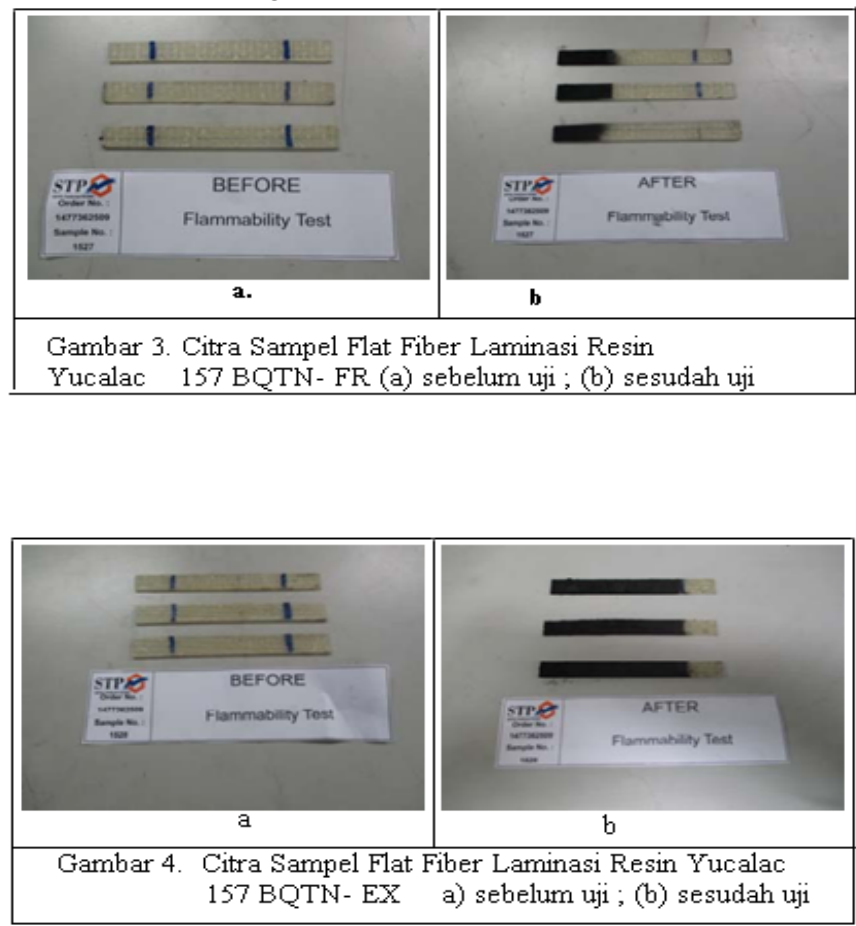

Penambahan aditif flame retardant memberi dampak pada perbaikan sifat bakar dimana sampel dengan flame retardant memiliki laju bakar yang lebih kecil. Hal ini disebabkan karena resin akan bereaksi membentuk ikatan silang dan laju 
bakar akan terhambat. Namun dari hasil pengujuan material tersebut belum diklasifikasikan sebagai material yang tahan api dan perlu penelitian lebih lanjut dengan penambahan aditif.

\section{SIMPULAN}

Dari hasil penelitian dan analsisa data dapat disimpulkan : Pertama Resin Yucalac BQTN-FR terbakar sampai dengan $40 \mathrm{~mm}$ (tanda $25 \mathrm{~mm}+15$ mm dari titik awal bakar; sedangkan Yucalac BQTN-EX terbakar habis hingga tanda $100 \mathrm{~mm}$, Kedua hasil penelitian ini menghasilkan komposisi terbaik dengan menggunakan resin Yucalac BQTNFR dengan laju bakar sebesar 16,2 $16.2 \pm 0.5 \mathrm{~mm} /$ menit dibandingkan dengan resin. Yucalac BQTN EX dengan laju bakar sebesar $22.8 \pm 0.3 . \mathrm{mm} /$ menit, dan ketiga bahwa kedua komposit belum dapat diklasifikasikan sebagai material tahan api.

Untuk bodi kapal tahan api perlu penelitian lanjut dengan penambahan aditif Flame retardant. agar mendapat klasifikasi V0 berdasarkan UL 94.

\section{DAFTAR PUSTAKA}

Efendi,AH., 2007, Natrium Sebagai Bahan Penghambat Api Aman Lingkungan, Journal Teknik Lingkungan,vol 8 No 3.h 245-252.

Friedman, R.1996, Principles of Fire Protection Chemistry,Association, New York.

Hull, D. and Clyne, T.W. 1996. An introduction to composite materials. Cambridge University Press, Cambridge.

Lyons, J.W., 1995, The Chemistry and Uses of Fire Retardant, John Wiley and Sons Inc., New York.

Sharifah, H.A., Martin, P.A., Simon, T.C. and Simon, R.P. 2005. Modified polyester resins fornatural fiber composites. Compos. Sci. Technol.65:525-535

Sinha, R., 2000. Outlines of Polymer Technology.Prentice-Hall by India private Ltd. New Delhi -10001

Smith W.F.,1993, Foundation of Materials Science ann Engiineering, Mc Graww Hill, Toronto

Surdia T dan Saito S. 2005. Pengetahuan Bahan Teknik. Pradnya Paramita, Jakarta. Satria, NJ, 2010, Analisa Pengaruh Luas Penampang Sambungan Terhadap Kekuaran Tarik Komposit PoliesterFiberglass. ITS,Surabaya

UL, 94, 2013, Test for Flammability of Plastic Materials for Parts in Devices and Appliances Underwriters Laboratories Inc. UL, 333 Pfingsten Road Northbrook, IL 60062 -2096.
Van P.,1994, Ilmu dan Teknologi Bahan, terjemahan Sriati J, Penerbit Erlangga, Jakarta. 